\title{
Oesophageal motor responses to gastro-oesophageal reflux in healthy controls and reflux patients
}

\author{
A Anggiansah, G Taylor, R E K Marshall, N F Bright, W A Owen, W J Owen
}

\begin{abstract}
Aims-To compare oesophageal motor responses to gastro-oesophageal reflux (GOR) in 16 healthy controls (group 1) and 25 reflux patients, 15 without (group 2) and 10 with (group 3) oesophagitis.

Methods-All subjects underwent 24 hour ambulatory oesophageal pH measurements $(5 \mathrm{~cm}$ above the lower oesophageal sphincter (LOS)) combined with pressure monitoring $(5,10$, and $15 \mathrm{~cm}$ above the LOS for oesophageal body motility and $27 \mathrm{~cm}$ above the LOS for voluntary swallow detection). Contraction patterns (peristaltic, simultaneous, isolated, mixed type, and non-transmitted swallows) and peristaltic contraction wave characteristics (amplitude, duration, and velocity) during GOR were compared in the three groups.
\end{abstract}

Results-The average number of motor activities per minute was significantly higher in group $1(p<0.05)$. In all groups, the most common motor contraction pattern was peristaltic. The percentage of peristaltic activity per subject was significantly higher in group $1(p<0.05)$. There were no significant differences in other contraction patterns among the three groups $(p>0.05)$. Of the peristaltic contraction wave characteristics there were no significant differences in any parameters (amplitude, duration, and velocity) among the three groups $(p>0.05)$. The average $\mathrm{pH}$ increment in response to motor activities was significantly higher in group $1(\mathrm{p}<0.05)$.

Conclusions-Motor responses to GOR were found to be predominantly primary peristaltic in all groups. During GOR, reflux patients have less frequent activity, a smaller proportion of activity is peristaltic, and the average pH increment in response to motor activities is reduced compared with controls.

(Gut 1997; 41: 600-605)

Keywords: acid clearance; ambulatory; oesophagus; $\mathrm{pH}$; pressure

Ambulatory long term pressure recording has become possible due to three developments: pressure sensor miniaturisation resulting in a smaller diameter pressure catheter ${ }^{1}$; the introduction of portable digital data recorders with an improved data compression technique ${ }^{2}$ or with a large storage capacity ${ }^{3}$; and the development and validation of automatic computer analysis which has made it possible to analyse long term oesophageal pressure data quickly, consistently, and objectively. ${ }^{4-6}$ Combined with $\mathrm{pH}$ monitoring, ambulatory pressure recording can be used to study oesophageal motor responses during gastro-oesophageal reflux (GOR) and to elucidate the mechanisms that lead to the restoration of a normal oesophageal $\mathrm{pH}$.

Oesophageal acid clearance after GOR depends on two important mechanisms: effective oesophageal peristalsis to return the displaced gastric contents to the stomach, ${ }^{7}$ and swallowing saliva to neutralise the residual acid coating the oesophageal mucosa. ${ }^{8}$ To evaluate acid clearance, previous studies have used a non-physiological method to simulate GOR by infusing a bolus of $0.1 \mathrm{M}$ hydrochloric acid into the oesophagus. The $\mathrm{pH}$ increments in response to swallows, taken on command at a fixed time interval, were monitored. ${ }^{9}$ Using ambulatory combined $\mathrm{pH}$ and pressure recording, motor responses during naturally occurring acid GOR have been reported in ambulant non-hospitalised reflux patients ${ }^{1011}$ and healthy subjects. ${ }^{12}$ This study aimed to investigate reflux induced motor activities in patients with proven pathological reflux, and to compare the findings with those from normal control subjects under ambulant conditions.

\section{Methods}

SUBJECTS

Subjects were divided into three groups. Group 1 consisted of 16 healthy controls (12 men, mean (SD) age 34.9 (11.6) years). Exclusion criteria were: a history of heartburn more than once every fortnight, dysphagia or regurgitation, the use of medications that interfere with oesophageal motility or gastric $\mathrm{pH}$, previous chest or upper abdominal surgery, diabetes mellitus, and any connective tissue or neurological disorder. Groups 2 and 3 consisted of 25 consecutive patients with heartburn, regurgitation, dysphagia, or chest pain, and pathological acid reflux on 24 hour ambulatory $\mathrm{pH}$ monitoring. Group 2 contained 15 patients $(13$ men, mean age 53.7 (12.6) years) with a normal oesophagus at endoscopy; group 3 contained 10 patients (nine men, mean age 45.4 (6.3) years) with endoscopic oesophagitis (Savary-Miller grade 1 or 2). $\mathrm{H}_{2}$ receptor antagonists and prokinetic agents were discontinued for 48 
hours and proton pump inhibitors for seven days prior to the study.

STATIC OESOPHAGEAL MANOMETRY AND 24 HOUR AMBULATORY pH MONITORING

All subjects underwent static manometry to exclude primary or secondary oesophageal motility disorders such as achalasia or scleroderma, followed by 24 hour ambulatory $\mathrm{pH}$ monitoring to confirm the presence of pathological GOR. Static manometry and 24 hour ambulatory $\mathrm{pH}$ monitoring have been described in our previous study. ${ }^{10}$ Briefly, static manometry was performed using a catheter with six surface mounted miniature pressure transducers (Gaeltec, Isle of Skye, UK) and an antimony $\mathrm{pH}$ catheter (Synectics Medical, Stockholm, Sweden) was inserted transnasally and positioned $5 \mathrm{~cm}$ above the manometrically defined upper margin of the lower oesophageal sphincter (LOS).

A reflux episode was defined as starting when the oesophageal $\mathrm{pH}$ fell below 4, and ending when the $\mathrm{pH}$ rose to 5 . Using commercially available software (Oesophagraph, Synectics Medical, Sweden), the total, upright, and supine reflux times, the number of reflux episodes, the number of reflux episodes longer than five minutes, the longest reflux episode, and the DeMeester score were calculated. ${ }^{13} \mathrm{~A}$ score greater than 14.7 (based on our estimate of the ninety fifth percentile of normal volunteers) indicated abnormal acid exposure, differentiating pathological from physiological reflux.

AMBULATORY PRESSURE AND $\mathrm{pH}$ MONITORING ASSEMBLY

The five pressure sensor catheter (Gaeltec, Isle of Skye, UK) consisted of a $5 \mathrm{~cm}$ long sensor to monitor LOS pressure (the Sphinctometer), ${ }^{14}$ three surface mounted miniature strain gauge pressure sensors placed $2.5 \mathrm{~cm}, 7.5 \mathrm{~cm}$, and $12.5 \mathrm{~cm}$ above the Sphinctometer to measure oesophageal body pressures, and a fifth pressure sensor $24.5 \mathrm{~cm}$ above the Sphinctometer to detect pharyngeal or cricopharyngeal activity associated with voluntary swallows. The Sphinctometer was positioned in a similar manner to the Dent Sleeve ${ }^{15}$ and recorded the integrated output of the pressure and length components of the LOS (the maximum length $\times$ pressure value occurring when its middle portion was positioned at the point of maximum LOS pressure). Therefore by positioning the four proximal sensors $2.5 \mathrm{~cm}, 7.5 \mathrm{~cm}$, $12.5 \mathrm{~cm}$, and $24.5 \mathrm{~cm}$ above it, the pressure points measured were $5 \mathrm{~cm}, 10 \mathrm{~cm}, 15 \mathrm{~cm}$, and $27 \mathrm{~cm}$ above the maximum LOS pressure. LOS data generated by the Sphinctometer can only be used qualitatively and will not be discussed further. An antimony $\mathrm{pH}$ catheter was bonded to the pressure catheter so that the $\mathrm{pH}$ sensor was $5 \mathrm{~cm}$ above the upper margin of the LOS. The pressure and $\mathrm{pH}$ catheters were introduced transnasally under local anaesthesia. After correct positioning of the Sphinctometer in the LOS, 10 wet swallows ( $5 \mathrm{ml}$ boluses) were given to ensure that the recorder was functioning. At the completion of the record- ing, data were downloaded onto the host computer for semiautomatic analysis.

PRESSURE AND $\mathrm{pH}$ RECORDING SYSTEM

All pressure and $\mathrm{pH}$ measurements were monitored simultaneously at eight samples per second (the minimum sampling rate for oesophageal peristaltic activity is six samples per second $)^{16}$ on a 24 hour ambulatory recording device (7-MPR, Gaeltec, Isle of Skye, UK). With an internal computer to record data in a compressed form, all pressure changes above a preset level of $6 \mathrm{~mm} \mathrm{Hg}$ were recorded. Baseline data points were only stored at two second intervals when pressure changes were less than $6 \mathrm{~mm} \mathrm{Hg}$, reducing stored data by a factor of between four and 20 . The resulting 24 hour recording used a maximum of $515 \mathrm{~KB}$ of disk space. Data were downloaded onto a 410/1 Acorn Archimedes computer (Acorn Computers, Cambridge).

AMBULATORY PRESSURE AND PH DATA ANALYSIS Oesophageal motor activity was defined as primary if the contraction waves in the body of the oesophagus were related to a pharyngeal pressure rise of greater than $20 \mathrm{~mm} \mathrm{Hg}$ or to cricopharyngeal swallowing activity, and secondary if the contraction waves were not related to pharyngeal or cricopharyngeal swallowing activity. Oesophageal motor activities were further classified as:

Peristaltic: defined as a time interval of 0.25-7 seconds between the peaks of contractions in two adjacent levels, $5 \mathrm{~cm}$ apart.

Simultaneous: defined as a time interval of less than 0.25 seconds between the peaks of contractions in adjacent levels.

Isolated: defined as a contraction detected at a single site when no appropriate matching contractions could be found at the other levels.

Reverse peristaltic: defined as occurring when the time interval between the peaks of the contractions in two adjacent levels was -0.25 to -1 seconds.

The motor patterns from the three channel pressure recording in the body of the oesophagus were grouped into four main contraction types: peristaltic, simultaneous, isolated, and mixed type (a mixture of peristaltic, simultaneous, and reverse peristaltic). Oesophageal motor responses to acid reflux were analysed as follows:

Automatic analysis of the pressure data was performed to classify the contraction patterns (peristaltic, simultaneous, isolated, or mixed type) and to evaluate the characteristics of the peristaltic contraction wave (amplitude, duration, and velocity).

From the analysis reflux table (containing information on all reflux episodes), the exact time of each reflux episode was identified and the contraction patterns and peristaltic contraction wave characteristics within each reflux period were noted. Manual analysis was used to identify whether contraction patterns in response to reflux were primary, secondary, or non-transmitted. 
TABLE 1 Percentage total, upright, and supine reflux times for groups 1, 2, and 3

\begin{tabular}{lccc}
\hline & Total reflux (\%) & Upright reflux (\%) & Supine reflux (\%) \\
\hline Group 1 $(\mathrm{n}=16)$ & $1.35(0.1-7.5)^{\star}$ & $2.05(0.2-8.6)^{\star}$ & $0.25(0-3.6)^{\star}$ \\
Group 2 $(\mathrm{n}=15)$ & $10.70(4.7-31.6)$ & $11.50(3.4-31.2)$ & $12.1(0-31)$ \\
Group 3 $(\mathrm{n}=10)$ & $9.10(2.7-26.4)$ & $9.45(0.6-22)$ & $8.75(0-34)$ \\
\hline
\end{tabular}

Values expressed as median percentage time (range).

${ }^{\star} \mathrm{p}<0.05$ group $1 v$ groups 2 and 3 .

TABLE 2 Number of reflux episodes, total reflux duration, and associated motor responses during GOR in the three groups

\begin{tabular}{|c|c|c|c|c|}
\hline & $\begin{array}{l}\text { Reflux } \\
\text { episode }\end{array}$ & $\begin{array}{l}\text { Total reflux } \\
\text { duration (min) }\end{array}$ & $\begin{array}{l}\text { Associated motor } \\
\text { activities }^{a}\end{array}$ & $\begin{array}{l}\text { Average number of } \\
\text { motor activities/min } \\
\text { Median (range) }\end{array}$ \\
\hline Group 1 $(n=16)$ & 459 & 465.6 & 706 (P:625; S:81) & $1.72^{\star}(0.34-5.38)$ \\
\hline Group $2(n=15)$ & 794 & 2623.0 & 1923 (P:1795; S:128) & $0.89 \quad(0.25-1.61)$ \\
\hline Group $3(n=10)$ & 579 & 1482.6 & 1263 (P:1156; S:107) & $0.88 \quad(0.41-1.82)$ \\
\hline
\end{tabular}

STATISTICAL ANALYSIS

Statistical tests based on a normal distribution were used for most analyses. However, the reflux parameters (total, upright, and supine percentage times) and the average number of motor activities per minute during GOR had skewed distributions and so non-parametric methods (the Kruskal-Wallis one way analysis of variance followed by a Mann-Whitney test) were used to compare the three groups with respect to these variables.

The percentages of each type of contraction were calculated across the three groups for each subject, and the mean percentages of each type of contraction (peristaltic, simultaneous, isolated, mixed type, and non-transmitted swallows) during GOR were compared. A one way analysis of variance followed by Tukey's multiple comparison test was used to compare the mean percentage of each type of contraction per subject across the three groups.

To compare the $\mathrm{pH}$ increment in response to motor activities (either all types of contraction together or peristaltic contraction alone) or to peristaltic contraction wave characteristics (amplitude, duration, and velocity) across the
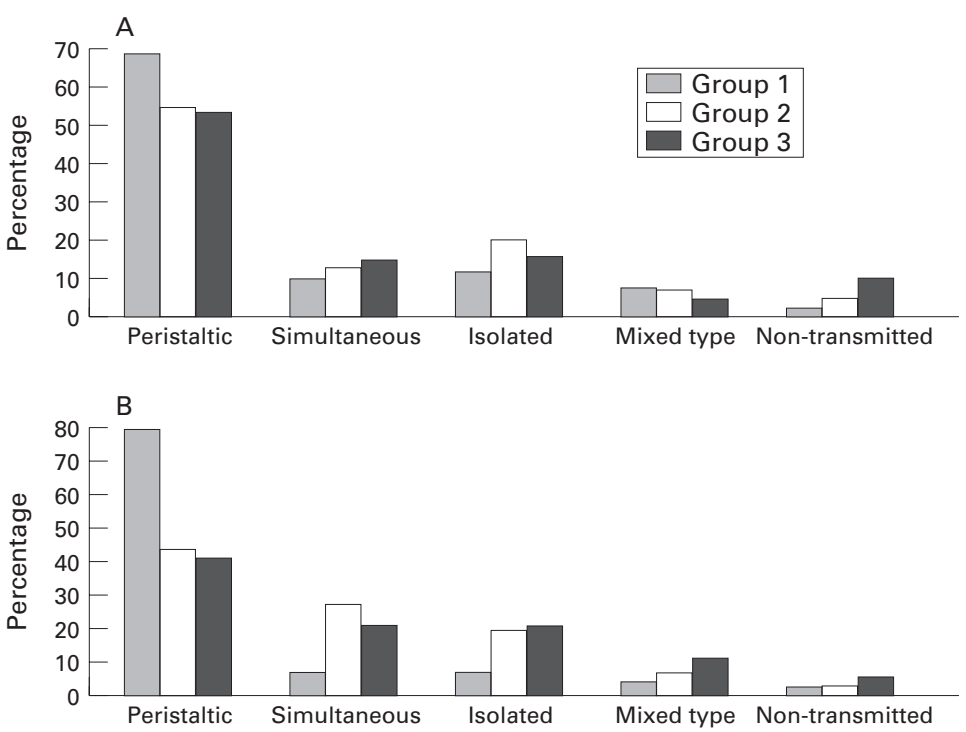

Figure 1: Percentages of different motor activities during GOR in the upright $(A)$ and supine (B) period. three groups, a repeated measures analysis of variance could not be used because different subjects occurred in different groups with widely varying numbers of repeated samples. A nested analysis of variance ${ }^{17}$ was felt to be the more appropriate method. A Tukey test for multiple comparisons was then performed to compare the $\mathrm{pH}$ increment in response to motor activities or peristaltic contraction wave characteristics across the three groups.

\section{Results}

REFLUX DATA

Table 1 shows the reflux parameters. When total, upright, and supine times for the three groups were compared, there was a significant difference between the groups $(p<0.01)$. For all three periods, groups 2 and 3 had significantly greater reflux than group 1 $(\mathrm{p}<0.01)$ and there was no significant difference between groups 2 and $3(p>0.05)$.

REFLUX EPISODES AND ASSOCIATED MOTOR RESPONSES DURING GOR

Table 2 shows the number of reflux episodes, duration of reflux, and the associated motor activities. In all groups, the percentage of secondary activity was small (less than $11.5 \%$ ) compared with primary activity. When the average number of motor activities per minute per group was compared, a significant difference was found $(p<0.01)$. In group 1 the average number of motor activities per minute (1.72) was significantly higher than that in group $2(\mathrm{p}<0.01)$ and group $3(\mathrm{p}<0.05)$. No significant difference was found between groups 2 and 3 ( $p>0.05)$.

DISTRIBUTION OF CONTRACTION PATTERN TYPES AND PRIMARY AND SECONDARY ACTIVITIES DURING GOR

Figure 1 shows the percentage distribution of motor activities (peristaltic, simultaneous, isolated, mixed type contractions, and nontransmitted swallows) during GOR for the three groups, evaluated in the upright (fig 1A) and supine (fig 1B) periods. These show that peristaltic contraction was the most common motor activity in all groups and in both periods. Group 1 had the highest percentage and group 3 the lowest percentage of peristaltic activity.

Figure 2 shows the percentages of primary (fig 2A) and secondary (fig 2B) activities within different contraction patterns during GOR. Peristaltic activity was the predominant primary motor contraction wave in the three groups. Secondary peristaltic activity was less common than other secondary non-peristaltic activities (simultaneous, isolated, and mixed type contractions); group 3 had the lowest percentage of secondary peristaltic activity but the highest percentage of secondary simultaneous activity. No secondary non-transmitted swallows were detected.

Statistical analysis was not performed for data from figs 1 and 2 individually as the range of percentages was too great and because there were no secondary non-transmitted swallows (fig 2B). Therefore only the percentages of each type of motor activity in each group were 

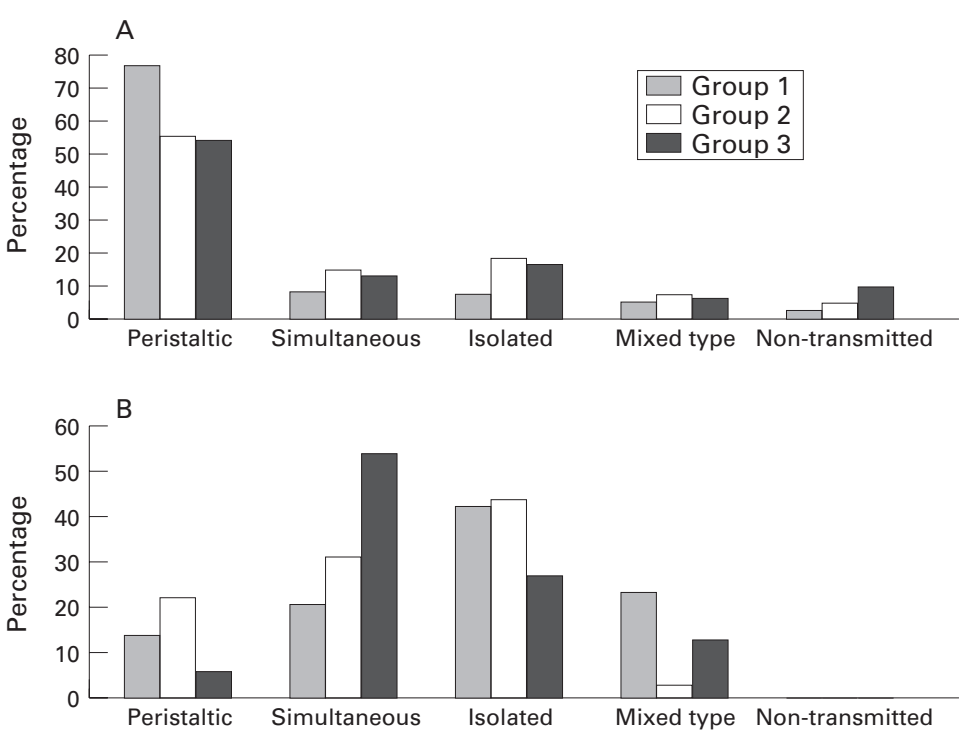

Figure 2: Percentages of different primary $(A)$ and secondary (B) activities during GOR.

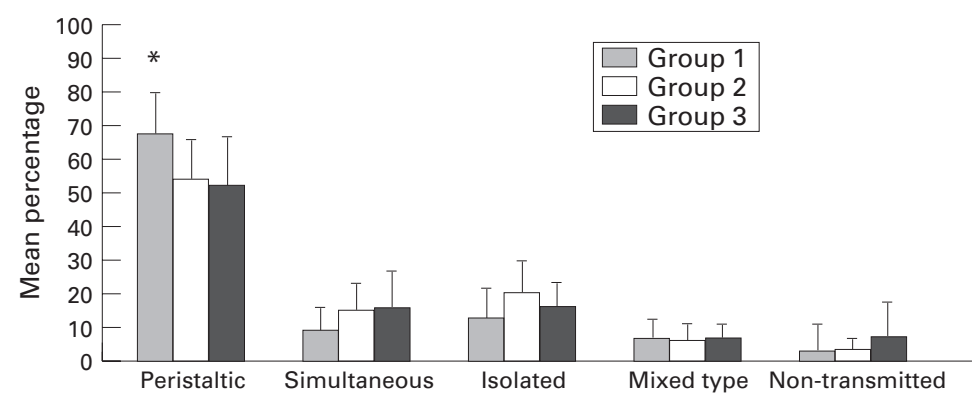

Figure 3: Comparison of the mean (SD) percentages of each of the five types of motor activity (peristaltic, simultaneous, isolated, mixed type contractions, and non-transmitted swallow) between the three groups. ${ }^{\star} p<0.05$ group $1 v$ groups 2 and 3.

calculated. Statistical analysis was performed to compare data between the three groups over the total period. It was inappropriate to analyse the data from the upright and supine periods, as very few data were obtained from the healthy controls (group 1) in the supine period.

Figure 3 shows the percentages of the five types of motor activities for the total period. It was found that the mean percentage of peristaltic activity per subject in group 1 was

TABLE 3 Mean (SD) percentage of peristaltic contractions in the three groups

\begin{tabular}{lllcl}
\hline & Percentage & Comparison & $95 \% C I^{\star}$ & $p$ Value \\
\hline Group 1 & $67.15(12.2)$ & Group 1-group 2 & 2.45 to 25.0 & $\mathrm{p}<0.05$ \\
Group 2 & $53.43(12.4)$ & Group 1-group 3 & 2.43 to 27.7 & $\mathrm{p}<0.05$ \\
Group 3 & $52.08(14.51)$ & Group 2-group 3 & -11.5 to 14.16 & $\mathrm{p}>0.05$ \\
\hline
\end{tabular}

${ }^{\star}$ The $95 \%$ confidence interval (CI) shows that it is $95 \%$ confident that the differences of means between group 1 and group 2, group 1 and group 3, and group 2 and group 3 lie between 2.45 and $25,2.43$ and 27.7 , and -11.5 and 14.16 , respectively, for the mean percentages of peristaltic activity during the total period.

TABLE 4 Mean (SD) pH increment in response to all motor activities in the total period

\begin{tabular}{lllcl}
\hline & $p H($ unit $)$ & Comparison & $95 \% C I^{\star}$ & $p$ Value \\
\hline Group 1 & $0.89(0.87)$ & Group 1-group 2 & 0.43 to 0.56 & $\mathrm{p}<0.05$ \\
Group 2 & $0.39(0.58)$ & Group 1-group 3 & 0.38 to 0.52 & $\mathrm{p}<0.05$ \\
Group 3 & $0.44(0.56)$ & Group 2-group 3 & -0.1 to 0.015 & $\mathrm{p}>0.05$ \\
\hline
\end{tabular}

$\star$ The $95 \%$ confidence interval (CI) shows that it is $95 \%$ confident that the differences of means between group 1 and group 2, group 1 and group 3, and group 2 and group 3 lie between 0.43 and $0.56,0.38$ and 0.52 , and -0.1 and 0.015 , respectively, for overall $\mathrm{pH}$ increment in response to all motor activities during the total period. significantly higher than that in groups 2 and 3 $(p<0.05)$ (table 3$)$. No significant difference in the mean percentage of peristaltic activity per subject was found between groups 2 and 3 $(p>0.05)$. For the other four types of motor activity (simultaneous, isolated, mixed type contractions, and non-transmitted swallow) no significant differences were found among the three groups.

pH INCREMENT IN RESPONSE TO MOTOR ACTIVITY The mean $\mathrm{pH}$ increment in response to all motor activities was significantly different for the total period $(\mathrm{p}<0.01)$ (table 4$)$. The mean $\mathrm{pH}$ increment in group 1 was significantly greater than that in groups 2 and $3(p<0.05)$. No significant difference was found between the reflux groups.

Figure 4 shows the $\mathrm{pH}$ increments in response to each individual type of motor activity in each group over the total time period. Statistical analysis was performed only on the average $\mathrm{pH}$ increments in response to peristaltic activity. For other types of motor activity the proportion was too small when compared with peristaltic activity, and only descriptive statistics were performed. The change in $\mathrm{pH}$ in group 1 (table 5) was significantly higher than that in groups 2 and 3 $(p<0.05)$. No significant difference was found between the reflux groups.

COMPARISON OF PERISTALTIC CONTRACTION WAVE CHARACTERISTICS (AMPLITUDE, DURATION, AND VELOCITY)

The mean peristaltic amplitude and duration for each group at each position $(5 \mathrm{~cm}, 10 \mathrm{~cm}$, and $15 \mathrm{~cm}$ above the LOS) in the oesophagus, and the mean peristaltic wave velocity (from $15 \mathrm{~cm}$ to $5 \mathrm{~cm}$ above the LOS) for each group were calculated. No significant differences in any of these parameters, at any position, were found among the three groups.

\section{Discussion}

The aim of this study was to investigate the motor responses during GOR in healthy controls (group 1), and reflux patients without oesophagitis (group 2) and with oesophagitis (group 3). Ideally, age matched controls should have been used, but the average age of healthy controls in this study was less than that of the reflux patients. A previous study ${ }^{18}$ has shown that there is no change in peristaltic amplitude, duration or LOS pressure in asymptomatic adults from age 15 to 74 years. Another study by Khan et $a l^{19}$ showed that there was only a minor decrease in oesophageal peristaltic amplitude and primary peristalsis when asymptomatic controls over 60 years of age were compared with asymptomatic controls under 40 years of age. The subjects used in this investigation have an average age of below 60 years, therefore the difference in age between controls and reflux patients should not have had a significant effect on the results.

Total, upright, and supine reflux times were significantly higher in the reflux groups (groups 2 and 3) when compared with healthy controls, agreeing with previous studies using 24 hour 


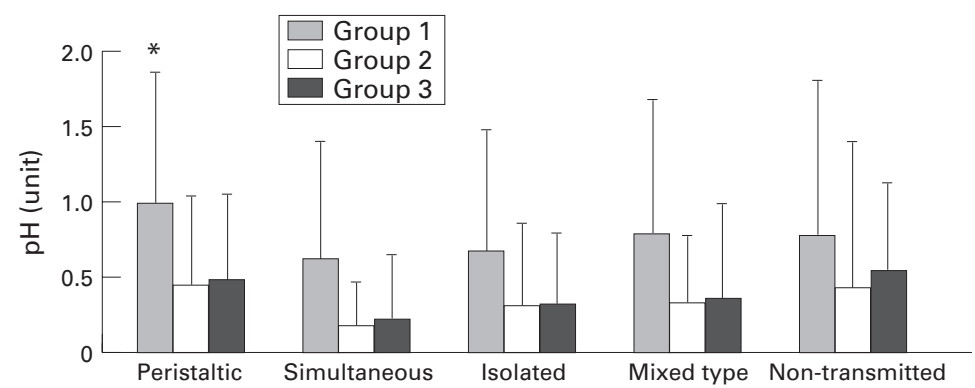

Figure 4: Mean (SD) pH increments in response to each type of motor activity during the total period.

TABLE 5 Mean (SD) pH increment in response only to peristaltic activity, and comparison among the three groups

\begin{tabular}{lllrl}
\hline & $p H$ (unit) & Comparison & $95 \% C I^{\star}$ & $p$ Value \\
\hline Group 1 & $0.99(0.88)$ & Group 1-group 2 & 0.44 to 0.61 & $\mathrm{p}<0.05$ \\
Group 2 & $0.46(0.63)$ & Group 1-group 3 & 0.41 to 0.59 & $\mathrm{p}<0.05$ \\
Group 3 & $0.49(0.58)$ & Group 2-group 3 & -0.11 to 0.05 & $\mathrm{p}>0.05$ \\
\hline
\end{tabular}

* The $95 \%$ confidence interval (CI) shows that it is $95 \%$ confidence that the differences of means between group 1 and group 2, group 1 and group 3, and group 2 and group 3 lie between 0.44 and $0.61,0.41$ and 0.59 , and -0.11 and 0.05 , respectively, for overall $\mathrm{pH}$ increment in response to peristaltic activity during the total period.

ambulatory oesophageal $\mathrm{pH}$ monitoring. ${ }^{20}$ There were no significant differences in the percentages of total, upright, and supine reflux between the two reflux groups. This may be a reflection of the relatively subjective nature of endoscopic grading in mild oesophagitis. A contributing factor may be that some patients had received prior acid suppression therapy from their referring specialists, altering the degree of endoscopic oesophagitis. Although it is true to say that the grade of oesophagitis tends to worsen with increasing acid exposure, this is not absolute: some patients have oesophagitis and a relatively short acid exposure time, and others have no oesophagitis and a considerably longer acid exposure time. The extent of oesophageal acid exposure cannot act as a predictor for the presence or absence of oesophagitis.

Although the control group had lower total, upright, and supine reflux times than the reflux groups, the average number of motor activities per subject in response to GOR was significantly higher. The importance of the frequency of oesophageal motor activity in acid clearance was shown by Paterson et al. ${ }^{21}$ They used combined ambulatory $\mathrm{pH}$ and pressure recording to study the effect of cisapride. They found that the mechanism responsible for the efficacy of cisapride in decreasing oesophageal acid exposure time was an increase in the number of oesophageal contractions, rather than an increase in the amplitude or duration of contractions. In this study we have demonstrated that control subjects have a greater frequency of motor activity in response to GOR compared with reflux patients. Therefore the higher frequency of motor responses to GOR may be one of the major factors leading to acid clearance.

The results of this study showing primary peristalsis to be the predominant contraction type leading to acid clearance are in agreement with those of our earlier study ${ }^{10}$ and with other studies. ${ }^{11} 1222$ The proposed trigger mecha- nisms for GOR induced oesophageal motor responses are either primary peristalsis induced by swallowing, or secondary peristalsis induced by oesophageal intraluminal distension. Studies of acid infusion or oesophageal distension have shown that both these events can stimulate secondary peristalsis. ${ }^{23}$ Therefore the initiation of secondary peristalsis was suggested to be important in limiting the duration of reflux episodes. ${ }^{24}$ This study demonstrated that during GOR, secondary activity is uncommon (less than $11.5 \%$ ) compared with primary activity. Even when secondary activity was stimulated, approximately $80 \%$ of this activity was non-peristaltic (simultaneous, isolated, and mixed type contractions) in all groups. This study is consistent with a recent study by Paterson et a $l^{25}$ who demonstrated that more than $70 \%$ of the balloon distension induced motor responses were non-peristaltic. The same study also demonstrated that the percentage of secondary peristalsis was much less than previously reported. ${ }^{26}$ Non-peristaltic activity is known to be ineffective in clearing the volume of the refluxate ${ }^{27}$ : even when the volume of refluxate is cleared by secondary activity, there is no saliva delivered to neutralise the remaining acid coating the oesophageal mucosa. Therefore this study confirms the conclusion drawn in previous studies,${ }^{10}{ }^{12}$ that secondary activity does not play an important role in acid clearance.

There was evidence from this study that the mean percentage of peristaltic activity was significantly lower in the reflux groups than in the control group, but the mean percentage of non-peristaltic activity (simultaneous, isolated, mixed type contractions, and non-transmitted swallow) was similar in all groups. This agrees with Bumm et $a l^{28}$ who reported that the frequency of oesophageal peristalsis during the GOR period was decreased in reflux patients. In this study, however, no clear explanation can be offered for the impairment of GOR induced peristalsis in reflux patients.

When the $\mathrm{pH}$ increments in response to all motor activities in the three groups were compared, the $\mathrm{pH}$ increment in the control group was significantly higher than that in the reflux groups. No significant difference was found between the reflux groups. The reason for the greater $\mathrm{pH}$ increment in response to all motor activities in the control group may be due to the significantly higher percentage of peristaltic activity in the control group when compared with the reflux groups. Peristaltic activity accounted for the greatest proportion of the entire motor activity, and this was then further investigated for its effect on $\mathrm{pH}$ increment. The average $\mathrm{pH}$ increment in response to peristaltic activity (table 5) was in concordance with the $\mathrm{pH}$ increment in response to all motor activities (table 4). In addition, this study shows that non-transmitted swallows can restore oesophageal $\mathrm{pH}$ (fig 4) - that is, ineffective motor activity (the amplitude of the non-transmitted swallow was less than $10 \mathrm{~mm}$ $\mathrm{Hg}$ ) was responsible for the $\mathrm{pH}$ increment and therefore another factor such as saliva must account for the $\mathrm{pH}$ increment. This evidence 
that a non-transmitted swallow can restore oesophageal $\mathrm{pH}$ supports the acid neutralising effect of saliva as documented by Helm et al. ${ }^{8}$

We found no significant differences in peristaltic contraction wave characteristics (amplitude, duration, or velocity) during GOR among the three groups. The magnitude of peristaltic amplitude $(>30 \mathrm{~mm} \mathrm{Hg}$ ) was established by $\mathrm{Kahrilas}^{9}$ as important in clearing reflux material (volume clearance) from the oesophagus, but in our study we were unable to measure volume changes during GOR. However, it demonstrated that the restoration of oesophageal $\mathrm{pH}$ did not depend on the magnitude of peristaltic amplitude, duration, or velocity. One possible explanation for the difference between controls and reflux patients was suggested by Barham et $a .^{29}$ They proposed that in patients with reflux disease further reflux episodes may superimpose on the original reflux episode, appearing to delay acid clearance. These findings are consistent with those of our earlier study ${ }^{30}$ and those of Allen et $a l,^{31}$ who showed no association between the $\mathrm{pH}$ increment and the magnitude of the peristaltic contraction amplitude, duration, and velocity. This again reinforces observations made by Paterson $e t a l^{21}$ in their study of acid clearance on cisapride therapy: the increase in the number of contractions is more important than the augmentation of contraction amplitude or duration in reducing the acid clearance time.

In conclusion, this study confirms that primary peristalsis is the major acid clearance mechanism in both normal subjects and reflux patients. In addition, we have shown that reflux patients have less frequent motor activity, a smaller proportion of which is peristaltic, and the average $\mathrm{pH}$ increment in response to motor activities during GOR is reduced, relative to controls.

We would like to thank Miss J Simpson for statistical advice. This work was presented to the British Society of Gastroenterology in abstract form, September 1995, Warwick University (Gut 1995; 37 (suppl 2): A46).

1 Akkermans LM. Esophageal manometry: microtransducers. Dig Dis Sci 1991; 36: 14S-16S.

2 Anggiansah A, Taylor G, Bright N, Wang J, Singh SD, Owen WA, et al. Comparisons of manual and automated analysis of oesophageal body contractility with on-line and compressed data. Gut 1994; 35 (suppl 5): S13

3 Emde C, Armstrong D, Bumm RK, Riecken EO, Blum AL Twenty-four hour continuous ambulatory measurement of oesophageal $\mathrm{pH}$ and pressure: a digital recording system and computer-aided manometry analysis. fournal of Ambulatory Motility 1990; 3: 47-62.

4 Breedijk M, Smout AJPM, Van Der Zouw C, Verwey H, Akkermans LM. Microcomputer-based system for 24-hour recording of esophageal motility and $\mathrm{pH}$ profile with automated analysis. Med Biol Eng Comput 1989; 27: 41-6.

5 Bumm R, Emde C, Armstrong D, Bauerfeind P, Blum AL. Ambulatory esophageal manometry: comparison of expert Ambulatory esophageal manometry: comparison of expert and compur.
6 Bremmer RM, Costantini M, Hoeft SF, Yasui A, Crookes $\mathrm{PF}$, Shibberu $\mathrm{H}$, et al. Manual verification of computer analysis of 24-hour esophageal motility. Biomed Instrum Technol 1993; 27: 49-55.

7 Helm JF, Dodds WJ, Riedel DR, Teeter BC, Hogan WJ, Arndorfer RC. Determinants of esophageal acid clearance in normal subjects. Gastroenterology 1985; 85: 607-12.

8 Helm JF, Dodds WJ, Pelc LR, Palmer DW, Hogan WJ, Teeter BC. Effect of esophageal emptying and saliva on clearance of

9 Kahrilas PJ. Esophageal motor activity and acid clearance. Gastroenterol Clin North Am 1990; 19: 537-50.

10 Anggiansah A, Taylor G, Bright N, Wang J, Rokkas T, Owen WA, et al. Primary peristalsis is the major acid clearance mechanism in reflux patients. Gut 1994; 35: 1536-42.

11 Bremner RM, Hoeft SF, Costantini M, Crookes PF, Bremner CG, DeMeester TR. Pharyngeal swallowing. The major factor in clearance of esophageal reflux episodes. Ann Surg 1993; 218: 364-9.

12 Barham CP, Gotley DC, Miller R, Mills A, Alderson D. Pressure events surrounding oesophageal acid reflux episodes and acid clearance in ambulant healthy volunteers. Gut 1993; 34: 444-9.

13 Johnson LF, DeMeester TR. Development of the 24-hour intraesophageal $\mathrm{pH}$ monitoring composite scoring system. In: DeMeester TR, Skinner DB, eds. Esophageal disorders: pathophysiology and therapy. New York: Raven, 1985: 561-9.

14 Gotley DC, Barham CP, Miller R, Arnold R, Alderson D. The sphinctometer: a new device for measurement of lower oesophageal sphincter function. Br F Surg 1991; 78: 933-5.

15 Dent J. A new technique for continuous sphincter pressure measurement. Gastroenterology 1976; 71: 263-7.

16 Castell JA, Richter JE, Castell DO. Comparison of effect of decreasing sampling rates on measurement of esophageal peristaltic amplitude and duration. Gastroenterology 1988; 95: 859 .

17 Snedecor GW, Cochran WG. Nested classification. In: Snedecor GW, Cochran WG, eds. Statistical methods. Iowa: State University Press, 1989: 247.

18 Csendes A, Guiraldes E, Bancalari A, Braghetto I, Ayala M. Relation of gastroesophageal sphincter pressure and esophageal contractile waves to age in man. Scand $\mathcal{F}$ Gastroenterol 1978; 13: 443-7.

19 Khan TA, Shragge BW, Crispin JS, Lind JF. Esophageal motility in the elderly. Dig Dis 1977; 22: 1049-54.

20 Johnson LF, DeMeester TR. Twenty-four hour pH monitoring of the distal esophagus. A quantitative measure of gastroesophageal reflux. Am $\mathcal{F}$ Gastroenterol 1974; 62: 325-32.

21 Paterson WG, Wang H, Beck IT. Ambulatory esophageal manometry/pH-metry in patients with reflux esophagitis: the effect of cisapride [abstract]. Gastroenterology 1994; 106: A157.

22 Dodds WJ, Kahrilas PJ, Dent J, Hogan WJ, Kern MK, Arndorfer RC. Analysis of spontaneous gastroesophageal reflux and esophageal acid clearance in patients with reflux esophagitis. F Gastrointest Motil 1990; 2: 79-89.

23 Thompson DG, Andreollo NA, McIntyre AS, Earlam RJ. Studies of the oesophageal clearance responses to intraluminal acid. Gut 1988; 29: 881-5.

24 Hankin LJ, Marples M, Bancewicz J. Does secondary peristalsis limit the duration of gastro-oesophageal reflux [abstract]? Gut 1989; 30: A727-8.

25 Paterson WG, Hynna-Liepert TT, Selucky M. Comparison of primary and secondary esophageal peristalsis in humans: effect of atropine. Am F Physiol 1991; 260: G52-7.

26 Creamer B, Schlegel M. Motor responses of the esophagus to distention. 7 Appl Physiol 1957; 10: 498-504.

27 Kahrilas PJ, Dodds WJ, Hogan WJ. Effect of peristaltic dysfunction on oesophageal volume clearance. Gastroenterology 1988; 94: 73-80.

28 Bumm R, Feussner H, Holscher AH, Jorg K, Dittler HJ, Siewert JR. Interaction of gastroesophageal reflux and esophageal motility. Evaluation by ambulatory 24-hour manometry and pH-metry. Dig Dis Sci 1992; 37: 1192-9.

29 Barham CP, Gotley DC, Miller R, Mills A, Alderson D. Oesophageal acid clearance in patients with severe reflux oesophagitis. Br F Surg 1995; 82: 333-7.

30 Anggiansah A, Taylor G, Bright N, Wang J, Singh SD, Owen WA, et al. Motor activity of the oesophagus probably only has a minimal effect on acid clearance [abstract]. Gut 1994; 35 (suppl 5): S7.

31 Allen ML, Dimarino AJ, Castell JA. Mechanism of esophageal acid clearance in supine heartburn patients [abstract] Gastroenterology 1994; 106: A39. 